\title{
Penentuan Penerima Bantuan Rumah Tidak Layak Huni Menggunakan Metode Simple Additive Weighting
}

\author{
Sonia Ratnaning P 1); Yustina Retno Wahyu Utami 2); Sri Harjanto ${ }^{3)}$ \\ 1)Program Studi S1 Sistem Informasi, STMIK Sinar Nusantara \\ 2)Program Studi S1 Informatika, STMIK Sinar Nusantara \\ ${ }^{3)}$ Program Studi D3 Sistem Informasi Akuntansi, STMIK Sinar Nusantara \\ 1) $17400055 . s o n i a @ s i n u s . a c . i d ;{ }^{2)}$ yustina_retno@sinus.ac.id; ${ }^{3)}$ sriharjanto@sinus.ac.id
}

\begin{abstract}
Uninhabitable Housing Assistance (RTLH) is a government program which distribute to village office, it has purpose to improve the life quality of community. Poor people can life convenient with Uninhibitable Houses Assistence. Determination of social assistence construction of Uninhabitable Houses is going to do by relying on the intitution. The purpose of this research is creating a decision support system that can help to determine the appropriate poor people are receiving social assistence of Uninhabitable House (RTLH) using simple additive weighting (SAW) method. It is used the creteria such as, the monthly income, the occupation, the total of burden, the condition of house wall, the condition of house floor, the condition of house roof, and the condition of bathroom. The result of this research is the beneficial system for receiver of Uninhabitable Houses.
\end{abstract}

Keywords: Decision Support System, Simple Additive Weighting, Uninhabitable Housing Assistance

\section{PENDAHULUAN}

Rumah Tidak Layak Huni (RTLH) dapat dikategorikan sebagai suatu hunian atau tempat tinggal yang tidak layak huni karna tidak memenuhi persyaratan untuk hunian baik secara teknis maupun non teknis. Rumah Tidak Layak Huni (RTLH) merupakan suatu program dari pemerintah yang disalurkan melalui kantor desa untuk memberi bantuan dana pembangunan rumah bagi warga kurang mampu.

Di Desa Dukuh Kecamatan Delanggu Kabupaten Klaten terdapat kuota bantuan pembangunan rumah tidak layak huni sebanyak 3 rumah pertahunnya, dengan bantuan berupa material bahan bangunan senilai 10 juta perrumah. Dengan banyaknya jumlah data masyarakat calon penerima bantuan dan keterbatasan kuota penerima bantuan rumah tidak layak huni yang ada, petugas harus bisa memprioritaskan masyarakat yang paling membutuhkan bantuan tersebut.

Berdasarkan uraian diatas, tujuan penelitian ini adalah merancang sistem penentuan penerima bantuan pembangunan rumah tidak layak huni. Penggunaan metode simple additive weighting pada sistem diharapkan dapat membantu pihak kelurahan dalam menentukan masyarakat yang berhak menerima bantuan Rumah Tidak Layak Huni berdasarkan perangkingan.
Sistem pendukung keputusan dibuat menggunakan bahasa pemrograman Visual Basic [1] yang datanya disimpan, diolah secara sistematis didalam komputer untuk menghasilkan informasi [2]. Penyimpanan database menggunakan Microsoft SQL Server, user dapat menyimpan banyak data dan mengimplementasikannya untuk kepentingan bisnis dan perusahaan [3].

\section{TINJAUAN PUSTAKA}

\subsection{Sistem Pendukung Keputusan}

Sistem pendukung keputusan atau Decision Support Sistem (DSS) merupakan sistem informasi interaktif yang menyediakan informasi, pemodelan, dan pemanipulasian data. Sistem itu digunakan untuk membantu pengambilan keputusan dalam situasi yang semiterstruktur dan situasi yang tidak terstruktur, dimana tak seorang pun tahu secara pasti bagaimana keputusan seharusnya dibuat [4].

\subsection{Simple Additive Weighting (SAW)}

Metode Simple Additive Weighting (SAW) merupakan suatu metode yang digunakan untuk mencari alternatif optimal dari sejumlah alternatif dengan kriteria tertentu. Inti dari SAW adalah menentukan nilai bobot untuk setiap atribut, kemudian dilanjutkan dengan proses perankingan yang akan menyeleksi alternatif 
yang sudah diberikan [5]. Adapun langkahlangkah dari metode SAW adalah:

a. Menentukan kriteria-kriteria yang akan dijadikan acuan dalam pengambilan keputusan.

b. Menentukan rating kecocokan setiap alternatif pada setiap kriteria.

c. Membuat matriks keputusan berdasarkan kriteria (C), kemudian melakukan normalisasi matriks berdasarkan persamaan yang disesuaikan dengan jenis atribut (atribut keuntungan ataupun atribut biaya) sehingga diperoleh matriks ternormalisasi R.

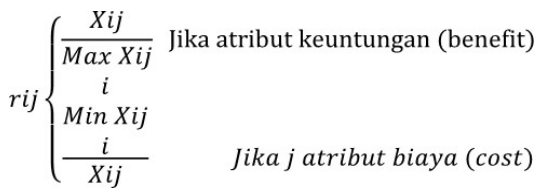

Dimana:

$r_{i j}=$ rating kinerja ternomalisasi

Max $X_{i j}=$ nilai maksimum dari setiap baris dan kolom

Min $X_{i j}=$ nilai minimum dari setiap baris dan kolom

$\mathrm{X}_{\mathrm{ij}}=$ baris dan kolom dari matriks

benefit = jika nilai terbesar adalah terbaik

cost $=$ jika nilai terkecil adalah terbaik

d. Hasil akhir diperoleh dari proses perankingan yaitu penjumlahan dari perkalian matriks ternormalisasi $\mathrm{R}$ dengan vektor bobot sehingga diperoleh nilai terbesar yang dipilih sebagai alternatif terbaik (A) sebagai solusi.

$V_{i}=\sum W_{j} r_{i j}$

Dimana:

$V_{i}=$ Nilai akhir dari alternatif

$\mathrm{W}_{\mathrm{j}}=$ Bobot yang telah ditentukan

$\mathrm{r}_{\mathrm{ij}}=$ Normalisasi matriks

Nilai $V_{i}$ yang lebih besar mengindikasikan bahwa alternatif $V_{i}$ lebih terpilih.

Pada penelitian lain yang berjudul Sistem Pendukung Keputusan Kategori Rumah Tidak Layak Huni Di Kelurahan Majidi Selong Kabupaten Lombok Timur Dengan Metode Simple Additive Weighting (SAW) yang diketahui bahwa Metode ini dapat memberikan nilai bobot pada setiap kriteria dan selanjutnya dilakukan perangkingan untuk mendapatkan keputusan siapa yang layak mendapat bantuan [6].

\section{METODE PENELITIAN}

Metode pengembangan sistem yang akan digunakan adalah model sekuensial atau sering disebut model waterfall yang merupakan model klasik yang bersifat sistematis, berurutan dalam membangun software [7].

\subsection{Analisa Sistem}

Pada tahapan ini penulis melakukan analisa terhadap kelemahan dan kebutuhan sistem pendukung keputusan tersebut. Langkah ini meliputi menentukan bobot kriteria sampai dengan menghitung rumusan dengan metode Simple Additive Weighting.

\subsection{Perancangan Sistem}

Pada tahapan ini penulis melakukan perancangan sistem dengan menggunakan Diagram Konteks, Hierarchy Plus Input-ProsesOutput (HIPO), Data Flow Diagram (DFD) yang dapat memberikan suatu tampilan secara visual, dan Entity Relationship Diagram (ERD). Langkah ini digunakan agar mudah dalam proses pengembangan sistem pendukung keputusan tersebut.

\subsection{Pengkodean (Coding)}

Tahap pengkodean (coding) adalah mengimplementasikan desain rancangan menjadi bentuk yang dimengerti oleh mesin dalam bentuk bahasa pemrograman dengan menggunakan software programming Visual Basic.Net dengan database Microsoft SQL Server.

\subsection{Pengujian}

Tahapan pengujian sistem langkah yang digunakan yaitu menguji kinerja dari berbagai fitur dari aplikasi menggunakan metode blackbox testing [8]. Dalam Pengujian kelayakan sistem, digunakan pengujian User Acceptance Test (UAT).

\section{HASIL DAN PEMBAHASAN \\ 4.1 Analisa Menggunakan SAW \\ A. Menentukan Data Alternatif}

Data alternatif merupakan suatu data yang didapat dari warga calon penerima bantuan RTLH ditunjukkan pada Tabel 1.

Tabel 1. Data Alternatif

\begin{tabular}{|l|l|}
\hline \multicolumn{1}{|c|}{ Kode } & \multicolumn{1}{|c|}{ Nama } \\
\hline A1 & Keluarga1 \\
\hline A2 & Keluarga2 \\
\hline A3 & Keluarga3 \\
\hline A4 & Keluarga4 \\
\hline A5 & Keluarga5 \\
\hline
\end{tabular}




\begin{tabular}{|l|l|}
\hline \multicolumn{1}{|c|}{ Kode } & \multicolumn{1}{|c|}{ Nama } \\
\hline A6 & Keluarga6 \\
\hline A7 & Keluarga7 \\
\hline A8 & Keluarga8 \\
\hline A9 & Keluarga9 \\
\hline A10 & Keluarga10 \\
\hline
\end{tabular}

B. Menentukan Bobot dan Nilai Kriteria Adapun bobot, nilai kriteria, dan nilai sub kriteria Rumah Tidak Layak Huni dapat dilihat pada Tabel 2 berikut.

Tabel 2. Data Kriteria

\begin{tabular}{|c|l|c|}
\hline \multicolumn{2}{|c|}{ Kriteria } & Bobot (W) \\
\hline C1 & Pendapatan Perbulan & $25 \%$ \\
\hline C2 & Jenis Pekerjaan & $15 \%$ \\
\hline C3 & $\begin{array}{l}\text { Jumlah Tanggungan } \\
\text { Jiwa }\end{array}$ & $15 \%$ \\
\hline C4 & Kondisi Dinding & $10 \%$ \\
\hline C5 & Kondisi Lantai & $10 \%$ \\
\hline C6 & Kondisi Atap & $10 \%$ \\
\hline C7 & MCK & $15 \%$ \\
\hline
\end{tabular}

Tabel 3. Data Sub Kriteria

\begin{tabular}{|c|c|c|}
\hline Kriteria & Sub Kriteria & Nilai \\
\hline \multirow{4}{*}{ C1 } & $<1.000 .000$ & 1 \\
\hline & $1.000 .000-1.500 .000$ & 2 \\
\hline & $1.600 .000-2.000 .000$ & 3 \\
\hline & $>2.000 .000$ & 4 \\
\hline \multirow{2}{*}{$\mathrm{C} 2$} & Tidak Tetap & 1 \\
\hline & Tetap & 2 \\
\hline \multirow{4}{*}{ C3 } & $1-2$ & 1 \\
\hline & $3-4$ & 2 \\
\hline & $5-6$ & 3 \\
\hline & $>=7$ & 4 \\
\hline \multirow{3}{*}{$\mathrm{C} 4$} & Bambu & 1 \\
\hline & Papan atau Triplek & 2 \\
\hline & Dinding & 3 \\
\hline \multirow{3}{*}{ C5 } & Tanah Saja & 1 \\
\hline & Beralas Karpet & 2 \\
\hline & Tegel atau Cor & 3 \\
\hline \multirow{3}{*}{ C6 } & $\begin{array}{l}\text { Bocor, Usuk Keropos, } \\
\text { Gordin Keropos }\end{array}$ & 1 \\
\hline & Bocor, Usuk Keropos & 2 \\
\hline & Bocor & 3 \\
\hline \multirow{2}{*}{$\mathrm{C} 7$} & Tidak Punya & 1 \\
\hline & Punya & 2 \\
\hline
\end{tabular}

\section{Memasukkan Nilai Alternatif}

Setiap alternatif mempunyai kriteria, berikut merupakan kriteria yang sudah diubah menjadi nilai dari sub kriteria.

Tabel 4. Data Nilai Alternatif

\begin{tabular}{|c|c|c|c|c|c|c|c|}
\hline \multirow{2}{*}{ Kode } & \multicolumn{7}{|c|}{ Kriteria } \\
\cline { 2 - 8 } & C1 & C2 & C3 & C4 & C5 & C6 & C7 \\
\hline A1 & 3 & 2 & 2 & 3 & 2 & 2 & 2 \\
\hline A2 & 3 & 2 & 2 & 2 & 2 & 2 & 1 \\
\hline A3 & 3 & 2 & 3 & 3 & 3 & 3 & 2 \\
\hline A4 & 2 & 1 & 2 & 3 & 2 & 1 & 1 \\
\hline A5 & 1 & 2 & 1 & 2 & 1 & 3 & 1 \\
\hline A6 & 3 & 2 & 1 & 3 & 2 & 3 & 2 \\
\hline A7 & 4 & 1 & 3 & 3 & 3 & 2 & 2 \\
\hline A8 & 1 & 1 & 1 & 3 & 2 & 3 & 2 \\
\hline A9 & 2 & 1 & 2 & 3 & 2 & 2 & 2 \\
\hline A10 & 1 & 1 & 2 & 2 & 1 & 3 & 1 \\
\hline
\end{tabular}

D. Normalisasi Matriks

Pada tahap ini, dilakukan perhitungan normalisasi matriks pada kriteria Pendapatan Perbulan.

$r 1=\underline{\min (3 ; 3 ; 3 ; 2 ; 1 ; 3 ; 4 ; 1 ; 2 ; 1)}$

$=1 / 3=0,3$

Dengan menggunakan langkah yang sama sesuai dengan rumus perhitungan maka didapatkan hasil sebagai berikut.

$$
r=\left(\begin{array}{ccccccc}
0,3 & 0,5 & 0,67 & 0,67 & 0,5 & 0,5 & 0,5 \\
0,3 & 0,5 & 0,67 & 1 & 0,5 & 0,5 & 1 \\
0,3 & 0,5 & 1 & 0,67 & 0,3 & 0,3 & 0,5 \\
0,5 & 1 & 0,67 & 0,67 & 0,5 & 1 & 1 \\
1 & 0,5 & 0,3 & 1 & 1 & 0,3 & 1 \\
0,3 & 0,5 & 0,3 & 0,67 & 0,5 & 0,3 & 0,5 \\
0,25 & 1 & 1 & 0,67 & 0,3 & 0,5 & 0,5 \\
1 & 1 & 0,3 & 0,67 & 0,5 & 0,3 & 0,5 \\
0,5 & 1 & 0,67 & 0,67 & 0,5 & 0,5 & 0,5 \\
1 & 1 & 0,67 & 1 & 1 & 0,3 & 1
\end{array}\right)
$$

E. Menentukan Pembobot Preferensi

Selanjutnya mencari nilai preferensi dengan cara perkalian matriks dengan bobot lalu dijumlahkan hasil perkaliannya. Berikut perhitungan untuk mencari nilai preferensi (V) pada alternatif 1 .

$$
\begin{aligned}
\mathrm{V} 1 & =(25 \cdot 0,3)+(15 \cdot 0,5)+(15 \cdot 0,67) \\
& +(10 \cdot 0,67)+(10 \cdot 0,5)+(10 \cdot 0,5) \\
& +(15 \cdot 0,5) \\
& =50
\end{aligned}
$$

Dengan menggunakan langkah yang sama sesuai dengan rumus perhitungan maka 
didapatkan hasil akhir seperti terlihat pada Tabel 5.

Tabel 5. Hasil Perangkingan Perhitungan

\begin{tabular}{|c|c|c|l|}
\hline Kode & Nilai & Ranking & \multicolumn{1}{|l|}{ Keterangan } \\
\hline A10 & 88,3 & 1 & Layak \\
\hline A5 & 75,8 & 2 & Layak \\
\hline A4 & 74,2 & 3 & Layak \\
\hline A8 & 67,5 & 4 & Tidak Layak \\
\hline A9 & 61,7 & 5 & Tidak Layak \\
\hline A2 & 60,8 & 6 & Tidak Layak \\
\hline A7 & 58,75 & 7 & Tidak Layak \\
\hline A3 & 51,6 & 8 & Tidak Layak \\
\hline A1 & 50 & 9 & Tidak Layak \\
\hline A6 & 43,3 & 10 & Tidak Layak \\
\hline
\end{tabular}

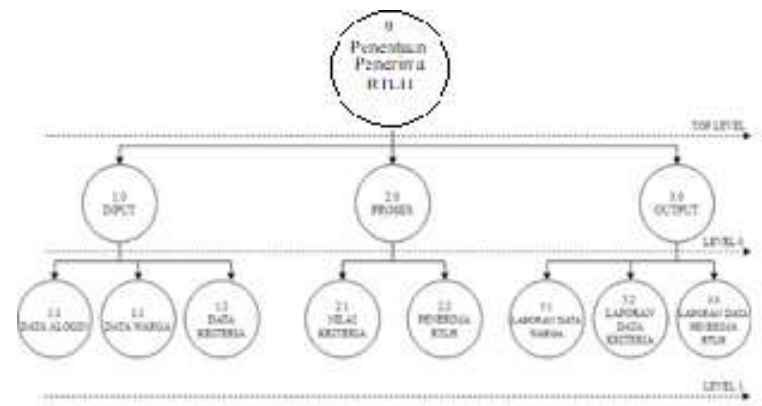

\section{Gambar 2. Diagram HIPO \\ C. Data Flow Diagram (DFD) \\ Data Flow Diagram (DFD) adalah media} untuk menjelaskan semua alur data beserta proses-proses yang terdapat di dalam sistem. DFD sistem ditunjukkan pada Gambar 3.

Dikarenakan kuota penerima bantuan RTLH hanya 3 keluarga, maka penerima ditentukan berdasarkan hasil 3 nilai tertinggi sebagai penerima bantuan RTLH.

\subsection{Perancangan Sistem}

\section{A. Diagram Konteks}

Diagram Konteks menggambarkan hubungan masukan atau keluaran pada sistem pendukung keputusan pemilihan penerima bantuan RTLH.

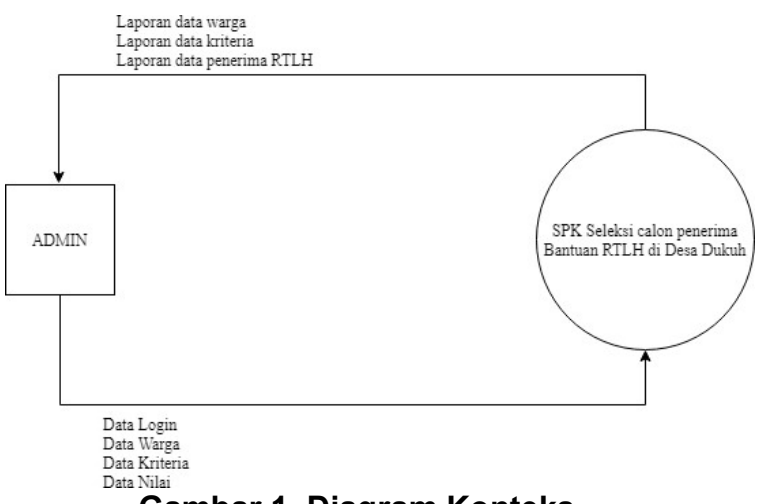

Gambar 1. Diagram Konteks

\section{B. Hierarchy Input Process Output (HIPO)}

Diagram ini menggambarkan tentang program secara terstruktur, yang berfungsi untuk memperjelas batasan program.

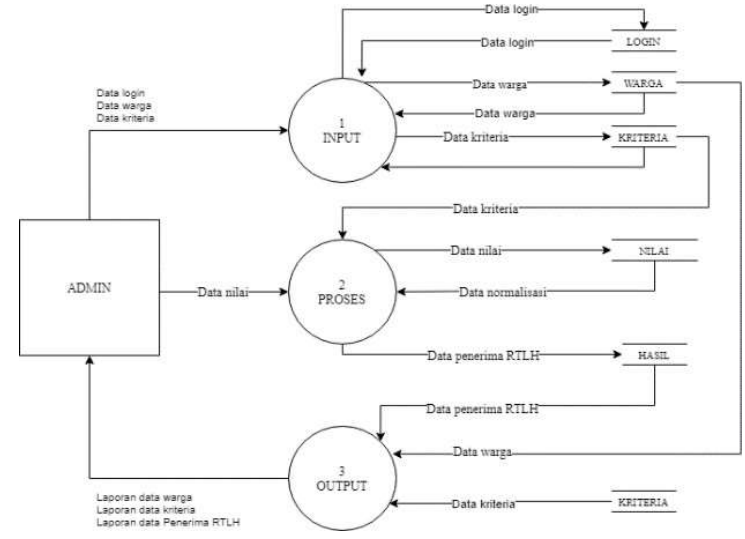

Gambar 3. Data Flow Diagram (DFD)

D. Entity Relationship Diagram (ERD)

Entity Relationship Diagram (ERD) bertujuan untuk menghubungkan struktur data antara satu sistem dengan sistem yang lainnya yang masih berhubungan, sehingga akan terlihat batasan hubungan dari semua sistem yang telah dibuat. ERD dari sistem yang diusulkan ditunjukkan pada Gambar 4.

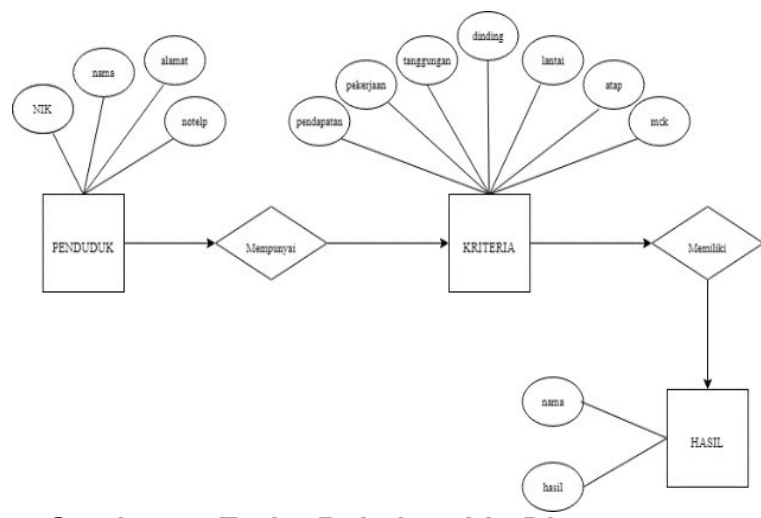

Gambar 4. Entity Relationship Diagram (ERD) 


\subsection{Implementasi Sistem}

Implementasi sistem pendukung keputusan pemilihan bantuan RTLH dengan menggunakan metode SAW, menampilkan input data warga, input kriteria penilaian dan hasil perhitungan.

Tampilan pada input data warga, digunakan untuk menambah data warga yang secara otomatis akan muncul pada halaman input kriteria penilaian. Input nilai kriterina terlihat seperti Gambar 5.

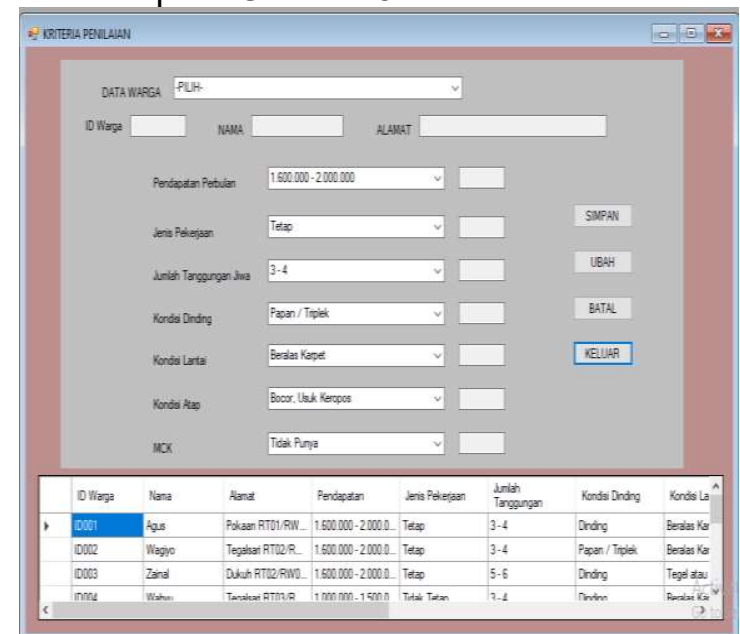

Gambar 5. Form Kriteria Penilaian

Setelah mengisi form kriteria penilaian, data akan diolah pada form hitung yang nantinya akan menampilkan hasil akhir penilaian, seperti ditunjukkan pada Gambar 6 .

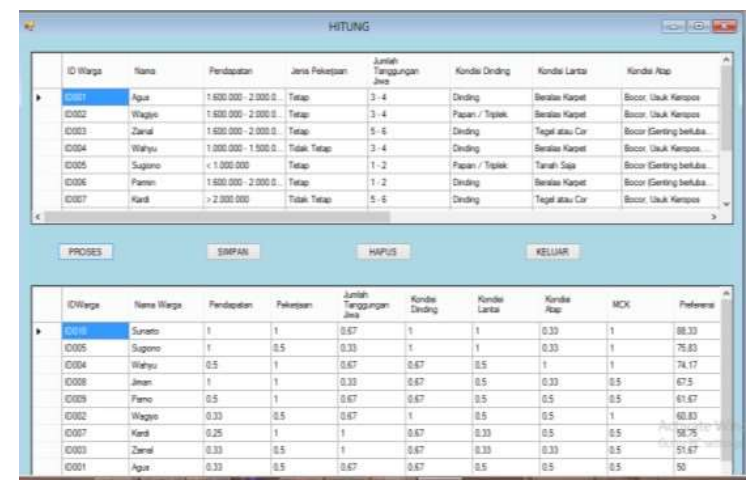

Gambar 6. Form Perhitungan

Hasil akhir berupa laporan penerima bantuan berdasarkan 3 nilai preferensi tertinggi, seperti ditunjukkan pada Gambar 7 .

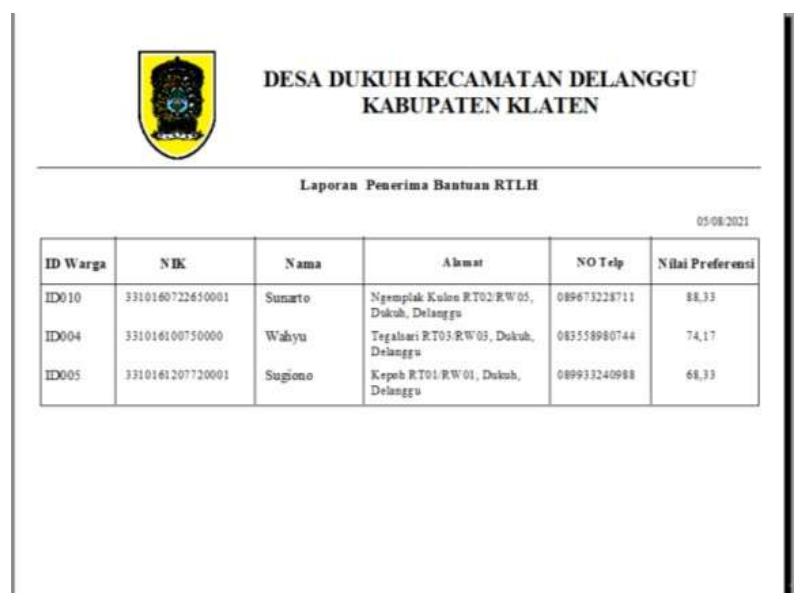

Gambar 7. Hasil Penerima RTLH

\subsection{Pengujian}

Untuk memastikan bahwa fungsi dari fiturfitur aplikasi ini dapat bekerja sesuai dengan konsep yang telah dirancang, maka dilakukan pengujian fungsional sistem menggunakan metode blackbox testing.

Pengujian kelayakan sistem menggunakan 5 responden dalam pengujian ini. Dalam pengujian kelayakan menggunakan skala 1-3. Hasil pengujian seperti Tabel 6.

Tabel 6. Hasil pengujian UAT

\begin{tabular}{|c|c|c|c|c|c|c|c|c|}
\hline \multirow{2}{*}{ No. } & \multirow{2}{*}{ Pertanyaan } & \multicolumn{3}{|c|}{$\begin{array}{c}\mathrm{Jml} \\
\text { responden }\end{array}$} & \multicolumn{3}{|c|}{ Nilai } & \multirow{2}{*}{$\mathrm{Jml}$} \\
\hline & & 3 & 2 & 1 & 3 & 2 & 1 & \\
\hline 1. & $\begin{array}{l}\text { Apakah tampilan } \\
\text { aplikasi sudah } \\
\text { sesuai? }\end{array}$ & 2 & 2 & 1 & 6 & 4 & 1 & 11 \\
\hline 2. & $\begin{array}{l}\text { Apakah aplikasi } \\
\text { ini mudah } \\
\text { digunakan? }\end{array}$ & 3 & 2 & 0 & 9 & 4 & 0 & 13 \\
\hline 3. & $\begin{array}{l}\text { Apakah pesan } \\
\text { informasi dapat } \\
\text { membantu dalam } \\
\text { menjalankan } \\
\text { aplikasi? }\end{array}$ & 4 & 1 & 0 & $\begin{array}{l}1 \\
2\end{array}$ & 2 & 0 & 14 \\
\hline 4. & $\begin{array}{l}\text { Apakah aplikasi } \\
\text { ini dapat } \\
\text { membantu dalam } \\
\text { menentukan } \\
\text { calon penerima } \\
\text { bantuan? }\end{array}$ & 3 & 2 & 0 & 9 & 4 & 0 & 13 \\
\hline 5. & $\begin{array}{l}\text { Apakah laporan- } \\
\text { laporan sudah } \\
\text { sesuai? }\end{array}$ & 3 & 1 & 1 & 9 & 2 & 1 & 12 \\
\hline \multicolumn{7}{|c|}{ Prosentase Keseluruhan } & & $84 \%$ \\
\hline
\end{tabular}

Berdasarkan Tabel 6, pengujian user kelayakan memperoleh hasil $84 \%$.

V. PENUTUP

5.1 Kesimpulan

1. Telah terbangunnya sistem penentuan penerima bantuan RTLH dengan 
menggunakan Metode SAW (Simple Additive Weighting) sebagai alat bantu untuk pengambilan keputusan dalam menentukan warga yang berhak mendapat bantuan renovasi rumah tidak layak huni.

2. Pengujian aplikasi menggunakan blackbox testing yang menunjukkan aplikasi dapat berfungsi dengan baik dilihat dari skenario dan hasil uji dimana hasil uji dapat diterima sistem. Pada Uji kelayakan berdasarkan kuisioner didapat hasil prosentase perhitungan sebesar $84 \%$.

\subsection{Saran}

1. Aplikasi Sistem Pendukung Keputusan yang telah dibuat masih cukup sederhana pada tampilan menunya karena lebih mengutamakan inti dari proses perhitungan dengan metode SAW.

2. Aplikasi ini terbatas pada kriteria tertentu dan belum terdapat adanya menu untuk penambahan kriteria, semoga pembaca bisa mengembangkan aplikasi ini dengan menambahkan menu kriteria.

\section{DAFTAR PUSTAKA}

[1] A.M Hirin, Belajar Tuntas (Dari Dasar Hingga Mahir) VB.Net 2010, Prestasi Pustaka, 2011.

[2] M. Hakim, Sistem Pendukung Keputusan Kategori Rumah Tidak Layak Huni Di Kelurahan Majidi Selong Kabupaten Lombok Timur Dengan Metode Simple Additive Weighting (SAW), Jurnal Matrik, Vol,17 NO.1., 2017.

[3] Jubilee, Otodidak Pemrograman Database Dengan Visual Basic, PT. Elex Media Komputindo, 2018.

[4] W. Komputer, SQL Server 2012. Yogyakarta: Andi, 2012.

[5] Kusrini, Konsep dan Aplikasi Sistem Pendukung Keputusan, Yogyakarta: Andi, 2007.

[6] S. N. Nangi Jumadil, Analisis Metode Simple Additive Weighting (SAW) dan Weighted Product dalam Penerimaan Karyawan Baru, Proceeding Seminar Nasional Aptikom, Mataram, 2016.

[7] R. S. Pressman, Rekayasa Perangkat Lunak. Yogyakarta: Andi Offset, 2002.

[8] P. William, Effective Methods for Software Testing. 1-5, 3-430, 1995. 